\title{
SRC-3 coactivator regulates cell resistance to cytotoxic stress via TRAF4-mediated p53 destabilization
}

\author{
Ping Yi, ${ }^{1}$ Weiya Xia, ${ }^{2}$ Ray-Chang $\mathrm{Wu}^{3}{ }^{3}$ David M. Lonard, ${ }^{1}$ Mien-Chie Hung, ${ }^{2}$ and Bert W. O'Malley ${ }^{1,4}$ \\ ${ }^{1}$ Department of Molecular and Cellular Biology, Baylor College of Medicine, Houston, Texas 77030, USA; ${ }^{2}$ Department \\ of Molecular and Cellular Oncology, The University of Texas M.D. Anderson Cancer Center, Houston, Texas 11030, USA; \\ ${ }^{3}$ Department of Biochemistry and Molecular Biology, George Washington University, Washington, DC 20037, USA
}

\begin{abstract}
Steroid receptor coactivator 3 (SRC-3) is an oncogenic nuclear receptor coactivator that plays a significant role in drug resistance. Using a lentiviral cDNA library rescue screening approach, we identified a SRC-3 downstream gene-TRAF4 (tumor necrosis factor [TNF] receptor associated-factor 4)-that functions in cell resistance to cytotoxic stress. TRAF4 expression is positively correlated with SRC-3 expression in human breast cancers. Similar to that observed for SRC-3 overexpression, breast cancer cells overexpressing TRAF4 are more resistant to stress-induced death. Here, we further dissected the underlying molecular mechanism for SRC-3 and TRAF4-mediated resistance to cytotoxic agents. We observed that SRC-3 expression is inversely correlated with the expression of p53-regulated proapoptotic genes in breast cancers and further found that SRC-3 and TRAF4 overexpression diminished cytotoxic stress-induced up-regulation of the tumor suppressor p53 protein. To determine the mechanism, we showed that the TRAF domain of TRAF4 bound to the N-terminal TRAF-like region of the deubiquitinase HAUSP (herpesvirus-associated ubiquitin-specific protease; also named USP7) and blocked the access of p53 to the same region of HAUSP. This TRAF4-mediated inhibition of HAUSP then led to the loss of p53 deubiquitination and its stabilization in response to cellular stress. Consistent with this cellular function, we also found that TRAF4 overexpression in breast cancer patients was associated significantly with poor prognosis. Because of SRC-3's ability to abrogate p53 function, our results suggest that SRC-3 overexpression may be especially important in tumors in which p53 is not mutated.
\end{abstract}

[Keywords: SRC-3; TRAF4; p53; deubiquitination; HAUSP; resistance]

Supplemental material is available for this article.

Received August 17, 2012; revised version accepted January 4, 2013.

Steroid receptor coactivator 3 (SRC-3/AIB1/ACTR/pCIP/ $\mathrm{RAC} 3 / \mathrm{Ncoa} 3$ ) is an oncogenic nuclear receptor coactivator. It interacts with nuclear receptors such as estrogen receptor (ER) to enhance target gene transcription upon hormone stimulation. SRC-3 was found to be overexpressed in $>60 \%$ of primary breast tumors, and its gene is amplified in 5\%-10\% of them (Anzick et al. 1997; Murphy et al. 2000). Transgenic mice overexpressing SRC-3 have an extremely high spontaneous mammary tumor incidence (Torres-Arzayus et al. 2004). High expression of SRC-3 is strongly correlated with shorter disease-free and overall survival (Zhao et al. 2003). SRC-3 not only functions to promote breast cancer development, it also participates in tamoxifen resistance. It is significantly associated with early recurrence within $2 \mathrm{yr}$ of follow-up evaluation (Dihge et al. 2008). High SRC-3 expression, together with

\footnotetext{
${ }^{4}$ Corresponding author
}

E-mail berto@bcm.edu

Article is online at http://www.genesdev.org/cgi/doi/10.1101/gad.203760.112. high HER-2 expression, is associated with the worst disease-free survival for patients receiving adjuvant therapy (Osborne et al. 2003; Kirkegaard et al. 2007).

Several lines of evidence imply that SRC-3 plays a role in drug resistance. Drug resistance is a primary cause for treatment failure in patients with metastatic cancer (Longley and Johnston 2005). It was recently found that amplification of chromosome 20q11.22-q13.12 is significantly associated with primary chemoresistance in ovarian cancers (Etemadmoghadam et al. 2009). The SRC-3 gene is mapped to this locus and is believed to be the most likely driver gene involved in this chemoresistance (Etemadmoghadam et al. 2009). Consistent with this interpretation, increased SRC-3 expression in ovarian cancer and esophageal carcinoma predicts chemoresistance and poor prognosis (Etemadmoghadam et al. 2009; He et al. 2009). A high SRC-3 protein level also correlates with resistance to EGFR antagonists in lung cancers (Cai et al. 2010). On the other hand, downregulation of the SRC-3 protein level is considered an 
important step for enhancing the ability of several anticancer agents to effectively combat cancers (Harper et al. 2009; Li et al. 2009a,b). Thus, the expression level of SRC-3 may be an important factor in controlling the responses of cancer cells to anti-cancer therapies. Nevertheless, the mechanism of how SRC-3 is involved in drug resistance is totally unclear. We reasoned that identifying SRC-3 target genes involved in regulating this process would help elaborate the molecular mechanism underlying its ability to promote resistance.

Cells respond to different stresses or extracellular signals by altering complicated intracellular signaling pathways. Downstream effectors are usually regulated by upstream genes at the transcriptional or post-transcriptional level, such as at the level of protein activity or protein turnover. One of the most common methods to identify downstream transcriptional target genes is from microarray analyses. It is a useful approach in identifying a gene expression profile that is regulated by a specific protein or altered by a specific signal. However, fishing a critical functional target from these microarray data is a daunting task. Furthermore, downstream targets that are regulated at the post-transcriptional level cannot be identified from the microarray studies. In the present study, we employ a "rescue strategy" to identify genes downstream from SRC-3 that specifically functioned in cell resistance to cytotoxic stress using a lentiviral cDNA library screening approach (Wu et al. 2012). Overexpression of the candidate gene by lentivirus is able to rescue the consequences of SRC-3 depletion on cell sensitivity to the induced stress. Using this approach, we found that tumor necrosis factor (TNF) receptor associated-factor 4 (TRAF4) is a major SRC-3-regulated downstream gene that is involved in this process.

TRAF4 belongs to the TRAF family, comprised of seven members. The family members share a common TRAF domain at the $\mathrm{C}$ terminus and are adaptor/scaffold proteins that couple TNF receptors and interleukin receptors to downstream signaling pathways. TRAFs mainly regulate the function of the immune system. TRAF4, however, is a unique member of the TRAF family in that it does not interact with the TNF receptor. It only interacts weakly with a few members of the receptor family under certain specific conditions (Kedinger and Rio 2007). TRAF4 also does not play a major role in the development and normal function of the immune system, except for facilitating the migration of immune cells /Cherfils-Vicini et al. 2008). TRAF4-deficient mouse studies indicate that TRAF4 is important for early embryogenesis; one-third of TRAF4 knockout mice are embryonic-lethal (Regnier et al. 2002). Surviving mice display tracheal, skeletal, and neural tube closure defects, potentially due to the loss of TRAF4dependent migration. In most adult tissues, TRAF4 is expressed at basal levels (Kedinger and Rio 2007). However, it is overexpressed and amplified in several human cancers, including breast cancer (Camilleri-Broet et al. 2007). Indeed, TRAF4 was initially identified by differential screening of cDNAs that are up-regulated in metastatic breast cancer (Regnier et al. 1995). Currently, its function in cancer development is not clear.
Here we demonstrate that breast cancer cells overexpressing TRAF4, similar to cells that overexpress SRC-3, are more resistant to nitric oxide-induced cell death. We further demonstrate that overexpression of TRAF4 diminished stress-induced p53 up-regulation and subsequent cell apoptosis via competitive binding with p53 to the deubiquitinase HAUSP (herpesvirus-associated ubiquitin-specific protease; also named USP7). These findings underscore the important interactive roles of SRC-3 and TRAF4 in mediating cell responses to cytotoxic stress. Consistent with its cellular function, we found that high nuclear expression of TRAF4 in human breast cancer tumors was significantly associated with poor survival.

\section{Results}

TRAF4 is a SRC-3 downstream gene that regulates cell responses to cytotoxic stress

In order to test the role of SRC-3 in cell sensitivity to cytotoxic agents, we generated two different SRC-3depleted cell lines. One was a breast cancer cell, MCF-7, stably integrated with a shRNA expression vector that specifically targets SRC-3. Another cell line was derived from SRC-3-null mouse mammary epithelial cells harboring the ras oncogene (Kuang et al. 2004). We found that SRC-3 deficiency makes both cells more sensitive to sodium nitroprusside (SNP; nitric oxide donor)-induced cell death (Fig. 1A,B). SRC-3 depletion also sensitized cells to induced cell death by doxorubicin, a widely-used chemotherapeutic agent (Supplemental Fig. S1).

To understand the mechanism of how SRC-3 regulates cell sensitivity to cytotoxic agents, we developed a "rescue screening" methodology to identify SRC-3-dependent downstream genes. Our strategy was to generate a lentiviral cDNA library and then infect lentiviruses into SRC3-null or knockdown cells. Infected cells that survived under the stress of nitric oxide should contain potential anti-cell-death genes. We successfully obtained several clones from the screening (Supplemental Table S1). Among them, we found a well-known ER targeted gene, Cathepsin D (CTSD), which has been implicated with chemoresistance in ovarian cancers (Bazzett et al. 1999; Leto et al. 2004). Estrogen-dependent expression of CTSD was reduced by siRNA against SRC-3, substantiating that it is a SRC-3-regulated gene (Fig. 2A). Identification of this protein in our screening suggested that our approach was valid. Additionally, we identified a novel SRC-3-regulated gene, TRAF4. As shown in Figure 2B, knockdown of SRC-3 by siRNA in MCF-7 cells significantly decreased TRAF4 expression. Consistent with this, TRAF4 expression also was reduced in a MCF-7 shSRC-3 stable cell line (Supplemental Fig. S2A). The shRNA targeted different sequences in SRC-3 from siSRC-3, indicating that the effects on TRAF4 expression are unlikely due to off-target effects of siRNA. Western blot analysis showed a decrease in TRAF4 protein level by siRNA against SRC-3 in either the absence or presence of SNP treatment (Supplemental Fig. S2B). In contrast, 
A

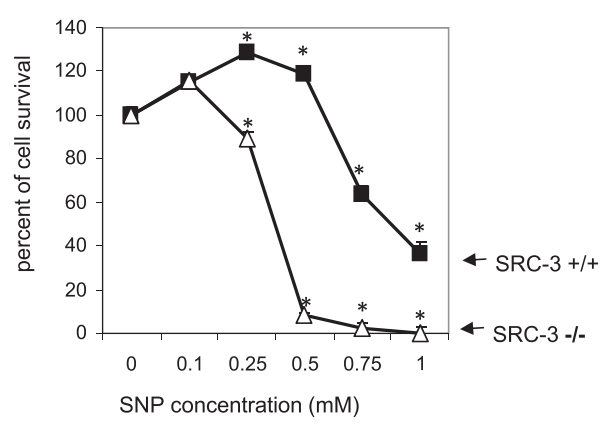

B

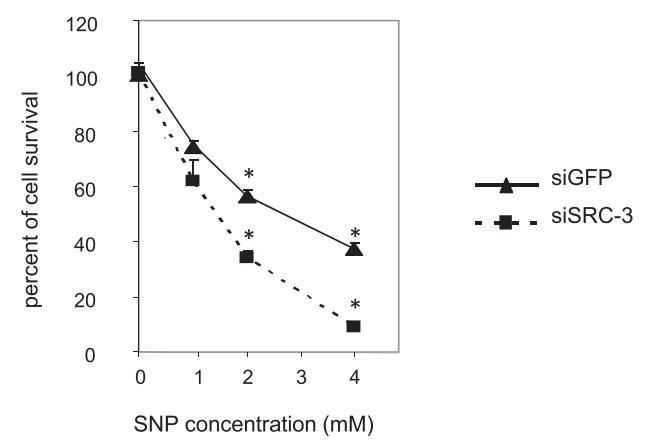

Figure 1. SRC-3 depletion sensitizes cells to nitric oxide-induced death. (A) SRC-3-deficient mouse mammary epithelial cells (SRC$3^{-l-}$ ) are more sensitive to SNP-induced cell death in comparison with wild-type cells $\left(\right.$ SRC- $\left.3^{+/+}\right)$. Cells seeded in a 96-well plate were treated with different concentrations of SNP for $1 \mathrm{~d}$. The percentage of cell survival was determined by MTS assay. ( $B$ ) SRC-3 knockdown by siRNA sensitized MCF-7 cells to SNP-induced death. Cells were transfected with $20 \mathrm{nM}$ siSRC-3 or siGFP for $2 \mathrm{~d}$. Different concentrations of SNP were then added into the medium for $1 \mathrm{~d}$ before assessing the percentage of surviving cells as described in A. $\left(^{\star}\right) P<0.05$. overexpression of SRC-3 in A549 cells significantly increased TRAF4 protein level (Supplemental Fig. S2C). These results further confirmed that SRC-3 regulated TRAF4 protein levels in the cells.

Using a human breast tumor array that contains 75 cases and 150 cores of breast normal and tumor tissues, we found that $67 \%$ of SRC-3 high-expressing samples also have higher levels of TRAF4, while $74 \%$ of TRAF4 highexpressing samples also have higher levels of SRC-3 (Fig. 2C). Representative images of SRC-3 high, TRAF4 high, SRC-3 low, and TRAF4 low tumor immunohistochemistry staining are shown in Supplemental Figure S3. The Pearson Product Moment correlation coefficient for the staining intensities of SRC-3 and TRAF4 in the breast tumor array is $0.442(P=0.00007218)$. We also analyzed the mRNA levels of SRC-3 and TRAF4 in a breast cancer cDNA array that contained 48 samples covering normal and different stages (stages I, IIA, IIB, IIIA, IIIB, IIIC, and IV) of breast tumors (Fig. 2D, left panel). Similar to that observed for the protein levels, the correlation between SRC-3 and TRAF4 mRNA levels is statistically significant. The scatter plot of the expression of SRC-3 and TRAF4 in these samples is shown in the right panel of Figure 2D. The correlation coefficient is $0.404(P=0.00445)$. These results suggest that SRC-3 also controls TRAF4 expression in breast tumors.

To understand how SRC-3 regulates TRAF4 expression, we generated several different TRAF4 promoter-driven luciferase constructs as reporters and found that SRC-3 is able to activate the $-1-\mathrm{kb}$ TRAF4 promoter-driven transcription (data not shown). We then searched for potential transcription factor-binding sites in this region and found that SRC-3 dramatically enhanced the activation activity of AP-1 (c-jun/c-fos) transcription factor on the $-1-\mathrm{kb}$ but not the $-0.4-\mathrm{kb}$ TRAF4 promoter-driven transcription (Supplemental Fig. S4A). Consistent with this, an AP-1 site was found within this region. Knockdown of c-fos in MCF-7 cells significantly reduced the TRAF4 mRNA levels (Supplemental Fig. S4B), suggesting that the AP-1 regulates endogenous TRAF4 transcription. It was previously known that SRC-3 directly interacts and coactivates AP-1 transcriptional activity (Lee et al. 1998; Yan et al. 2008). To test whether SRC-3 regulates TRAF4 transcription through AP-1, we performed a chromatin immunoprecipitation (ChIP) assay. As shown in Supplemental Figure S4C, both c-fos and SRC-3 can be recruited to the TRAF4 - 1-kb promoter but not the $3^{\prime}$ untranslated region (UTR) region. Knockdown of c-fos significantly reduced the recruitment of both c-fos and SRC-3, suggesting that SRC-3 directly regulates TRAF4 transcription through the AP-1 transcription factor.

To confirm that TRAF4 overexpression is indeed responsible for cancer cell resistance to SNP-induced death, we generated lentiviruses expressing TRAF4 and infected them into MCF-7shSRC-3 cells to establish a stable cell line. We used fewer lentiviruses to infect cells in order to obtain stable cells that express TRAF4 within a reasonable range to avoid gross overexpression. As shown in Figure 2E, the level of TRAF4 in the stable cells was about twofold the level found in control cells. The TRAF4 stable cells display less cell death compared with control cells at the same concentration of SNP. Similar results were obtained from TRAF4-overexpressing LNCaP cells (Supplemental Fig. S5C). In contrast, knockdown of TRAF4 by 
A

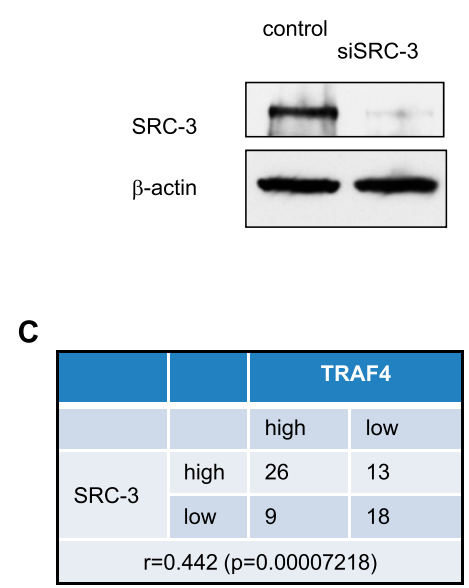

E

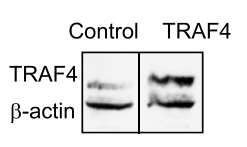

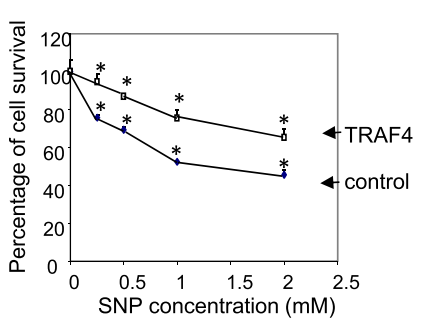

B
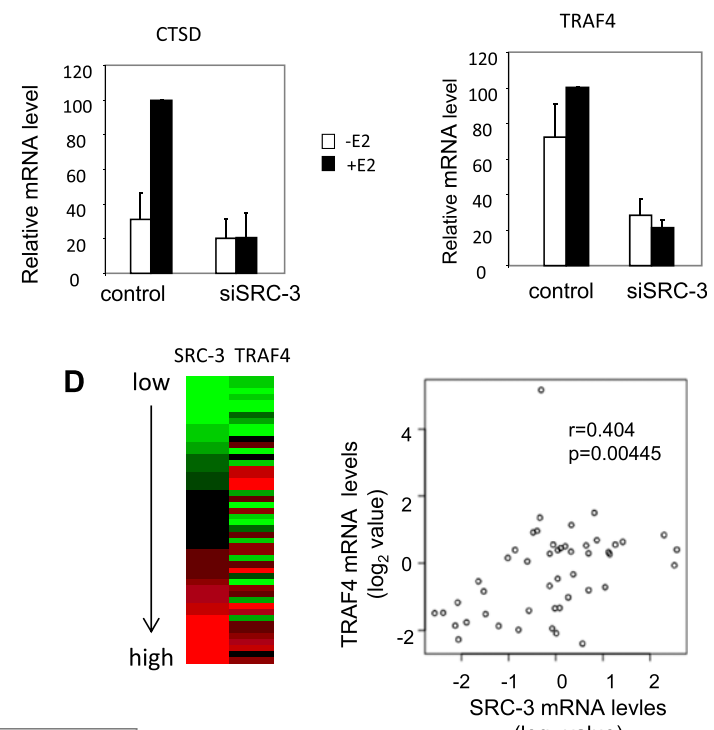

( $\log _{2}$ value)

Figure 2. TRAF4 is a SRC-3-regulated gene. (A) Knockdown of SRC-3 by siRNA decreased estrogen-dependent CTSD transcriptions compared with scramble control siRNA. (Left panel) Western blot analysis of SRC-3 protein levels in control or siSRC-3-treated MCF-7 cells. (Right panel) mRNA levels of CTSD as assessed by real-time quantitative PCR (qPCR). MCF-7 cells were treated with $10 \mathrm{nM}$ estradiol or vehicle for $16 \mathrm{~h} .(B)$ siSRC-3 decreased TRAF4 mRNA levels independent of estrogen treatment as assessed by real-time qPCR. $(C)$ The distribution of breast tumor tissue array samples according to high or low expression of SRC-3 and TRAF4. $r$ represents the Pearson Product Moment correlation coefficient of SRC-3 and TRAF4 expression in all samples. (D) The SRC-3 and TRAF4 mRNA expression levels are significantly correlated in breast cancers. (Left panel) The mRNA expression profile of SRC-3 and TRAF4 in 48 breast cancer samples. Samples were arranged from low to high according to SRC-3 levels. Green represents low expression. Red represents high expression. (Right panel) The scatter plot of the correlation between SRC-3 and TRAF4 mRNA levels. (E) TRAF4overexpressing stable cells are more resistant to SNP-induced cell death. (Left panel) TRAF4 protein levels in TRAF4 or empty vector stably expressing MCF-7shSRC-3 cells. Western blot analysis using TRAF4-specific antibody is shown. (Right panel) Percentage of cell survival under different SNP concentrations as described in Figure 1A. $\left(^{\star}\right) P<0.05$.

siRNA sensitized cells to SNP treatment (Supplemental Fig. S5A,B). We also found that TRAF4 stable cells were more resistant to doxorubicin treatment compared with control cells (Supplemental Fig. S5D,E). This implies that TRAF4 could inhibit the common death pathways that are induced by both nitric oxide signaling and doxorubicin. Thus, although TRAF4 was identified from SNP screening, it also could have important clinical relevance to doxorubicin or resistance to other chemotherapeutic agents in breast cancer patients.

\section{SRC-3 and TRAF4 regulate p53 protein levels}

We next investigated the mechanism by which SRC-3 and TRAF4 might regulate cellular responses to druginduced stress. Most chemotherapeutic agents or other anti-cancer drugs induce tumor cell apoptosis. MCF-7 cells are deficient in caspase-3, a commonly activated caspase in apoptosis (Janicke et al. 1998). To examine whether the cell death that we observed induced by nitric oxide was caused by apoptosis, MCF-7 cells were stained with Annexin-V and propidium iodide (PI). The existence of Annexin-V-positive and PI-negative staining of nitric oxide-treated cells indicated that cells were undergoing apoptosis (Supplemental Fig. S6), while the control cells without any treatment were alive, since they were negative for either Annexin- $\mathrm{V}$ or PI staining.

In searching for the mechanism of how SRC-3 might regulate anti-apoptosis, we found an apparent inverse correlation between SRC-3 protein levels and the levels of a proapoptotic protein, BID, enlisted in 410 breastinvasive carcinoma samples present in The Cancer Genome Atlas (TCGA) data sets (University of California at Santa Cruz [UCSC] Cancer Genomics) as assayed by reverse-phase protein array technology (Fig. 3A). BID is a member of the Bcl-2 family of proteins and is a p53regulated "chemosensitivity gene" (Sax et al. 2002). We downloaded the protein expression data of SRC-3 and BID 
A

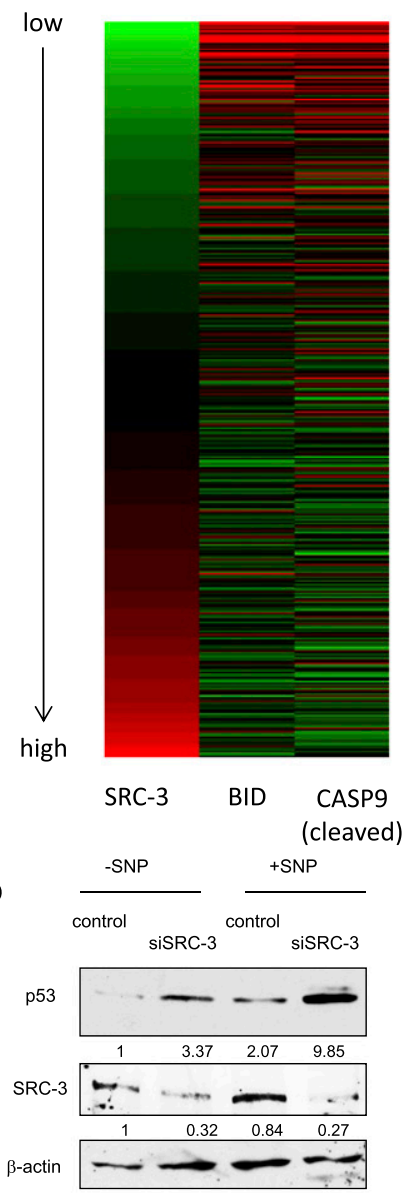

$\mathbf{F}$

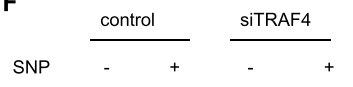

p53

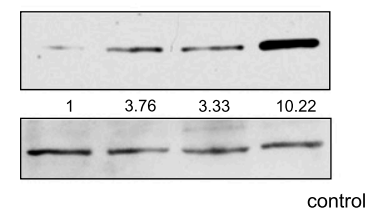

G
B

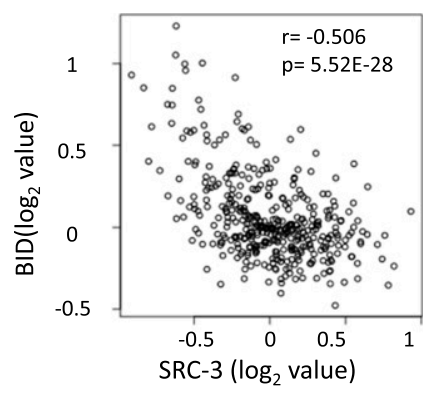

C

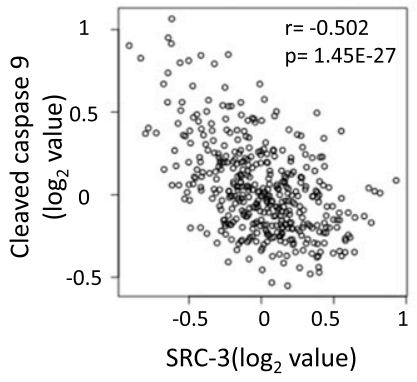

E

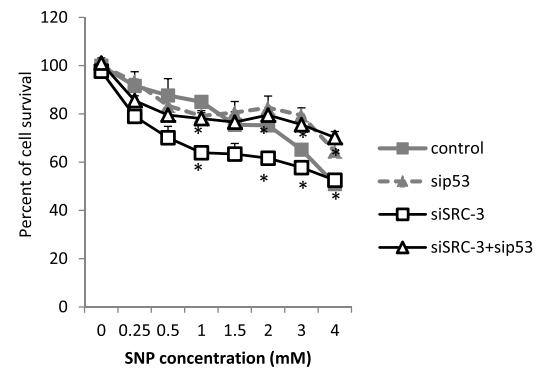

Figure 3. SRC-3 and TRAF4 regulate p53 induction. $(A)$ The protein expression profile of SRC-3 (AIB1), BID, and cleaved caspase 9 in TCGA breast-invasive carcinoma data set $(N=410)$ from UCSC Cancer Genomics. The protein levels were assayed by reverse-phase protein array technology. Samples were arranged from low to high according to SRC-3 protein levels. Green represents low expression. Red represents high expression. $(B)$ The scatter plot of the correlation between BID and SRC-3 protein levels in the 410 breast tumor samples. $r$ represents the Pearson Product Moment coefficient. (C) The scatter plot of the correlation between cleaved caspase 9 and SRC-3 protein levels. (D) SRC-3 knockdown increased p53 protein level. MCF-7 cells were treated with siSRC-3 or scramble control siRNA for $3 \mathrm{~d}$ and then treated with $2 \mathrm{mM}$ of SNP for $4 \mathrm{~h}$. (E, top panel) p53 knockdown increased the survival rate of siSRC-3 transfected MCF-7 cells under SNP treatment conditions. (Bottom panel) The level of p53 protein when cells were treated with control or sip53 (Dharmacon Smart Pool). (F) TRAF4 knockdown increased p53 protein level. $(G)$ p53 protein was more stable in siTRAF4 transfected cells in the presence of SNP. MCF-7 cells transfected with control or siTRAF4 were treated with SNP for $2 \mathrm{~h}$ followed by the addition of 200 $\mu \mathrm{g} / \mathrm{mL}$ cycloheximide for $0,1,2$, and $3 \mathrm{~h}$. The cell lysates were then subjected to Western blot analysis using a p53-specific antibody. $(H)$ p53-regulated gene transcription was up-regulated by TRAF4 knockdown. $\left(^{\star}\right)$ $P<0.05$.

H

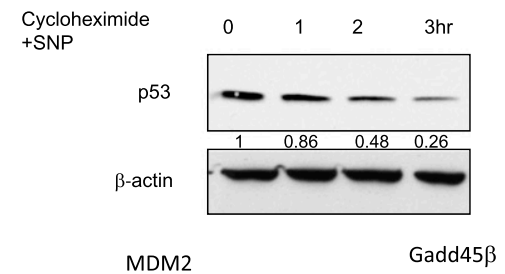

Gadd 5 (

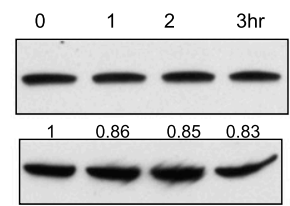

Bax

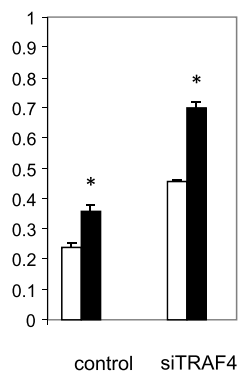

$\square-S N P$

- +SNP 
from UCSC Cancer Genomics and then performed statistical analysis. The scatter plot of SRC-3 and BID protein expression in these tumor samples is shown in Figure 3B. The Pearson correlation coefficient is $-0.506(P=5.52 \times$ $10^{-28}$, indicating that the SRC-3 and BID protein levels are indeed inversely correlated in breast tumors. Since BID is a proapoptotic protein, we then examined whether there is an inverse correlation between the expression of SRC-3 and apoptosis marker genes. Indeed, we found that the levels of SRC-3 protein and cleaved caspase 9 also are inversely correlated in breast cancers (Fig. 3A,C). These results suggest that SRC-3 could negatively regulate apoptosis in breast cancers.

Since the transcription of BID is regulated by the tumor suppressor p53, we then asked whether SRC-3 might negatively regulate $\mathrm{p} 53$ function. $\mathrm{p} 53$ protein level is usually induced upon stress or cytotoxic agent treatment. It is a critical factor for cell cycle arrest and cell apoptosis. We first examined whether SRC-3 depletion could affect p53 protein levels. As shown in Figure 3D, SNP treatment of MCF-7 cells significantly increased p53 protein levels. SRC-3 depletion in the presence of SNP dramatically increased p53 protein levels. In contrast, overexpression of SRC-3 significantly decreased p53 protein levels in the presence of SNP (Supplemental Fig. S7A). Furthermore, knockdown of p53 in SRC-3-depleted cells led to enhanced cell resistance to SNP or doxorubicin-induced cell death (Fig. 3E; Supplemental Fig. S8A). These results suggest that p53 plays an important role in SRC-3-regulated cell responses to cytotoxic stress. We then examined whether TRAF4 functions in the same pathway. As shown in Figure 3F and Supplemental Figure S7B, p53 protein level was significantly increased when TRAF4 was knocked down by a specific siRNA, which was similar to the effect of SRC-3 knockdown (Fig. 3D). We used two different siTRAF4s to ensure that increase of p53 protein levels in the presence of SNP were not caused by off-target effects of siRNA (Supplemental Fig. S7C). Similar to SRC-3 overexpression, TRAF4 overexpression in SNP or doxorubicin-treated LNCaP cells also decreased p53 protein levels (Supplemental Fig. S7D,E, respectively). Knockdown of p53 enhanced cell resistance to either cytotoxic agent-induced death (Supplemental Fig. S8B-D). To determine whether up-regulation of the p53 protein level occurs at the transcription level, we measured the mRNA level of p53 by real-time RT-PCR and did not observe a significant change when TRAF4 was knocked down (Supplemental Fig. S9A). Our results suggest that TRAF4 affects the post-transcriptional regulation of p53. The p53 protein stability then was determined by the treatment of cells with the protein synthesis inhibitor cycloheximide. As shown in Figure $3 \mathrm{G}$, the p53 protein level was degraded with time in the presence of control siRNA, while its protein was more stable in the absence of TRAF4, suggesting that TRAF4 interfered with the p53 protein turnover.

To determine whether the stabilized p53 caused by siTRAF4 was functionally active, p53-mediated gene transcription was examined. As shown in Figure $3 \mathrm{H}$, the levels of the p53-regulated genes MDM2, Gadd45, and Bax were up-regulated by siTRAF4, suggesting that siTRAF4mediated p53 stabilization has functional consequences on genes downstream from $\mathrm{p} 53$.

\section{TRAF4 interacts with the deubiquitinating enzyme HAUSP}

We next wanted to understand how TRAF4 regulates p53 protein level. p53 is polyubiquitinated and degraded by the $26 \mathrm{~S}$ proteasome. Under normal conditions, MDM2, an E3 ubiquitin ligase, binds to p53 and promotes its degradation. When cells are under stress, MDM2 is dissociated from p53, and its protein level is up-regulated.

p53 ubiquitination is dynamically regulated. The protein also undergoes deubiquitination catalyzed by HAUSP, resulting in its stabilization (Li et al. 2002). HAUSP contains a TRAF-like domain at its $\mathrm{N}$ terminus. This region mediates the interaction of HAUSP with p53 (Hu et al. 2006; Sheng et al. 2006). Interestingly, TRAF4 also interacts with HAUSP through this TRAF-like domain in vitro (Zapata et al. 2001). We further tested whether this interaction exists in cells. A coimmunoprecipitation (co-IP) experiment was carried out in MCF-7 cells using TRAF4 antibody or an IgG control. HAUSP was specifically coimmunoprecipitated by the TRAF4 antibody but not the IgG control (Fig. 4A). A similar interaction was observed in LNCaP prostate cancer cells, which also express wild-type p53 (Supplemental Fig. S9B). These results suggest that TRAF4 indeed interacts with HAUSP in cells.

We then asked whether the TRAF4-induced degradation of p53 may result from the inhibition of HAUSP's ability to stabilize p53. Since HAUSP mediates p53 deubiquitination, we first asked whether TRAF4 could affect HAUSP-mediated p53 deubiquitination. 293T cells were cotransfected with myc-tagged p53 and HA-tagged ubiquitin in the absence or presence of HAUSP or TRAF4 cotransfection. Cells were treated with SNP and the proteasome inhibitor MG132 to prevent the degradation of ubiquitinated p53. myc-p53 was then immunoprecipitated with an anti-myc antibody, and ubiquitinated p53 was detected using an anti-HA antibody. As shown in Figure 4B, cotransfection of HAUSP significantly decreased p53 polyubiquitination. Addition of TRAF4 abolished the deubiquitination effect of HAUSP toward p53. To determine whether TRAF4 affected the interaction between HAUSP and p53, a co-IP experiment was performed in myc-p53 and Flag-HAUSP transfected cells in the absence or presence of cotransfected TRAF4. The proteasome inhibitor MG132 was added to the cells to prevent p53 degradation in order to obtain an equal amount of myc-p53 as input. As shown in Figure 4C, the interaction between myc-p53 and FlagHAUSP was significantly reduced in the presence of TRAF4. Furthermore, a weaker interaction between endogenous p53 and HAUSP was observed in TRAF4overexpressing cells (Fig. 4D). These results suggest that TRAF4 was able to interfere with the interaction of p53 with HAUSP and decreased the HAUSP-mediated p53 deubiquitination. 
A

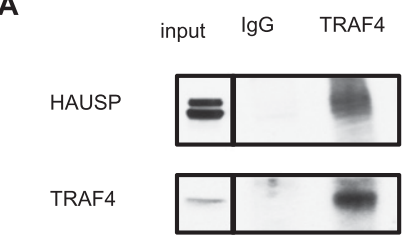

C

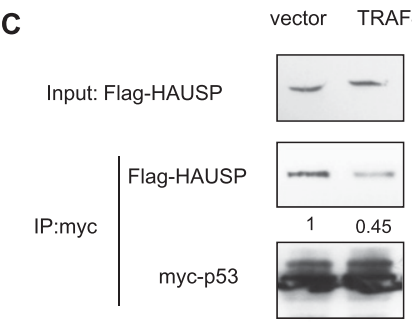

D

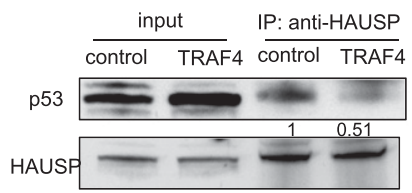

B

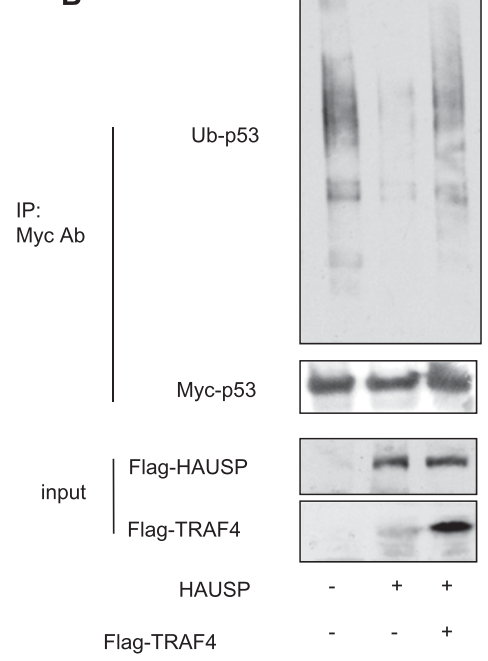

Figure 4. TRAF4 interacted with HAUSP and decreased HAUSP-mediated p53 deubiquitination. (A) TRAF4 interacted with HAUSP. Co-IP was carried out in MCF-7 cells using a TRAF4specific antibody. HAUSP was detected using a specific antibody in TRAF4 immunoprecipitated fractions. (B) TRAF4 decreased HAUSPmediated p53 deubiquitination. 293T cells were transfected with myc-p53 and HA-Ub in the absence or presence of cotransfection of expression vectors for Flag-HAUSP and Flag-TRAF4 for $2 \mathrm{~d}$. Cells were then treated with $20 \mu$ M MG132 and $2 \mathrm{mM}$ SNP for $4 \mathrm{~h}$ before harvesting. The ubiquitinated p53 was precipitated from cell lysates using a myc-specific antibody and was detected using a HA antibody for Western blot analysis. (C) TRAF4 decreased the interaction between p53 and HAUSP. 293T cells were transfected with myc-p53 and Flag-HAUSP in the absence or presence of cotransfected expression vectors for Flag-TRAF4 for $2 \mathrm{~d}$. Cells were then treated with $10 \mu \mathrm{M}$ MG132 and $2 \mathrm{mM}$ SNP for $4 \mathrm{~h}$ before harvesting. The interaction between HAUSP and p53 was detected by co-IP using a myc antibody followed by a Flag antibody detection and Western blot analysis. (D) The interaction between endogenous p53 and HAUSP was decreased in TRAF4-overexpressing stable cells. Cells were treated with MG132 in order to prevent p53 degradation, and therefore, equal amounts of p53 can be used as inputs. Co-IP was performed using a HAUSP-specific antibody, and the associated p53 was detected using a p53-specific antibody. (Control) Empty vector integrated stable cells; (TRAF4) TRAF4 stable cells.

\section{TRAF4 competes with p53 for HAUSP binding}

The fact that TRAF4 interacts with the same domain in HAUSP as p53 raises the possibility that TRAF4 may compete with p53 for binding to HAUSP. A similar mechanism was used by MDM2 (Hu et al. 2006; Sheng et al. 2006) and the viral protein nuclear antigen 1 (EBNA1), which protects cells from apoptosis and subsequent cell transformation upon Epstein-Barr virus infection by lowering p53 levels (Saridakis et al. 2005). MDM2 also is deubiquitinated by HAUSP. It binds to HAUSP at the same domain as p53 but in a mutually exclusive manner. TRAF4 overexpression has a minor effect on the interaction between MDM2 and HAUSP (Supplemental Fig. S9B). This likely may be due to much higher affinity of MDM2 with HAUSP compared with p53 (Hu et al. 2006). We wanted to examine whether TRAF4 is a competitor of p53 for HAUSP binding. p53, HAUSP, and TRAF4 proteins were synthesized using an in vitro transcription and translation system and mixed together for $30 \mathrm{~min}$ before co-IP with a HAUSP-specific antibody. As shown in Figure 5A, p53 interacts with HAUSP in vitro. The addition of TRAF4 abolished this interaction. Our result suggests that TRAF4 can compete with p53 for binding to HAUSP.

To confirm that this competition was not due to nonspecific interaction between TRAF4 and HAUSP, we first identified the HAUSP-interacting region in TRAF4 and then examined whether a TRAF4 deletion mutant without this interacting region was able to block the
p53-HAUSP interaction. A schematic representation of the TRAF4 protein domains is shown in Figure 5B. It contains an N-terminal RING finger motif, which has potential E3 ubiquitin ligase activity. The middle part of TRAF4 is composed of three cysteine-rich domains (CART [cysteine-rich domain associated with RING and TRAF domain]), which contains putative zinc finger domains. The $\mathrm{C}$ terminus contains the TRAF domain, which is responsible for homo- or heterodimerization and its interaction with TNF receptor family members. To analyze the regions important for TRAF4 functions, an expression vector for Flag-tagged wild-type, RING, CART, or TRAF domain-deleted TRAF4 was generated and transfected into 293T cells. A GST pull-down experiment was then performed using GST-fused HAUSP N-terminal TRAF-like domain (1-212 amino acids) and cell lysates expressing these TRAF4 mutants. The wild type was pulled down by GST-HAUSP but not GST, suggesting a specific interaction between TRAF4 and HAUSP (Fig. 5C, lane 6 vs. lane 5). The RING domain and the CART domain were dispensable for the interaction, since the deletion mutants $(\Delta \mathrm{R}$ and $\triangle \mathrm{CART})$ can still be pulled down by GST-HAUSP (Fig. 5C, lanes 7,8). The TRAF domain deletion mutant was very unstable and did not express well in cells. Alternatively, a combined RING and TRAF domain double deletion mutant $(\Delta \mathrm{R} / \mathrm{T})$ was generated, and no interaction was observed between this mutant and HAUSP (Fig. 5C, lane 9). These results suggest that the C-terminal TRAF domain is required for TRAF4 interaction with HAUSP. 
A

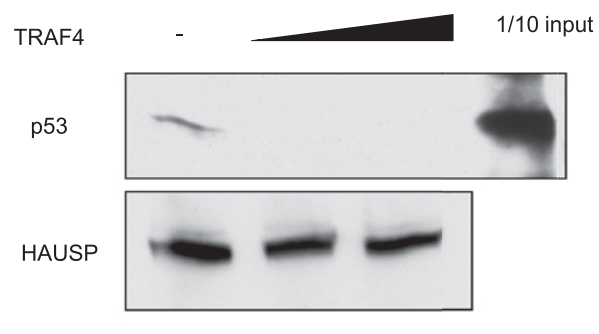

IP with anti-HAUSP antibody

D
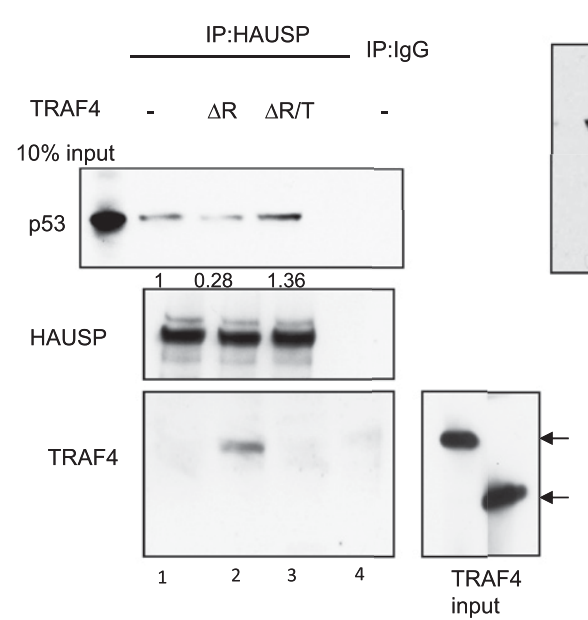

B
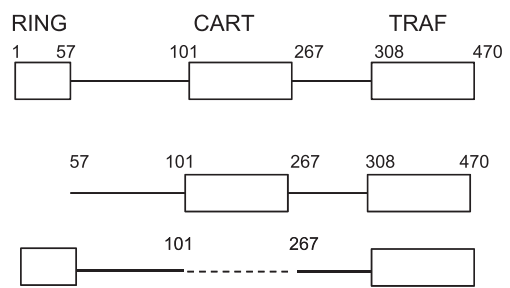

57
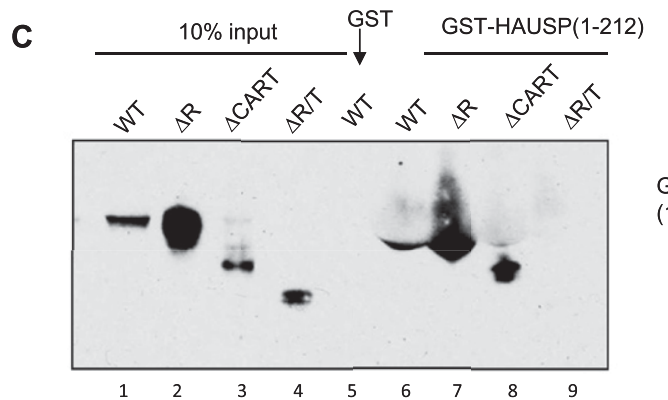

GST-HAUSP (1-212)

GS
E

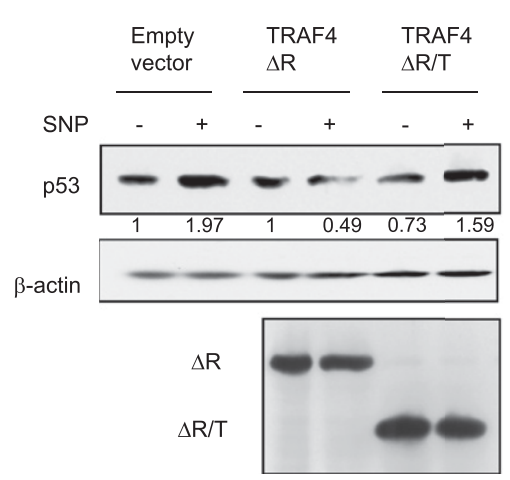

$\mathbf{F}$

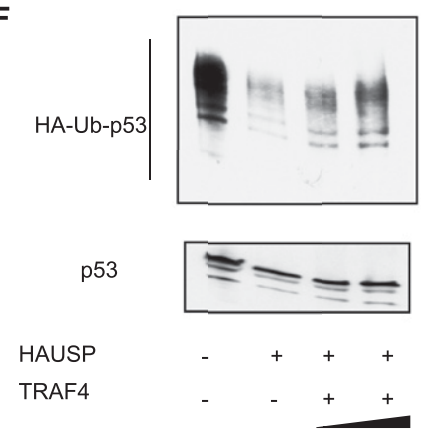

Figure 5. TRAF4 competed with p53 for HAUSP binding. (A) TRAF4 prevented p53 binding to HAUSP in vitro. p53, HAUSP, and TRAF4 were all synthesized using an in vitro transcription and translation system. p53 was incubated with HAUSP in the absence or presence of TRAF4 $(10$ and $20 \mu \mathrm{L})$. The mixture was subjected to co-IP using a HAUSP antibody followed by Western blot analysis using a p53 antibody. (B) Schematic representations of TRAF4 wild type (WT) and the $\Delta \mathrm{R}(\Delta 1-57), \Delta \mathrm{CART}(\Delta 101-267)$, and $\Delta \mathrm{R} / \mathrm{T}(\Delta 1-57,308-$ 470) mutants. (C) The TRAF domain is important for TRAF4 binding to HAUSP in vitro. Different Flag-tagged TRAF4 deletion mutants were transfected into 293T cells. The cell lysates were then incubated with GST- or GST-HAUSP-bound glutathione agarose beads. (Left panel) Western blot analysis of GST-HAUSP-associated TRAF4 mutants using a Flag antibody. (Right panel) Coomassie blue staining of purified GST or GST-HAUSP (1-212 amino acids). ( $D$ ) The TRAF domain is indispensable for the ability of TRAF4 to prevent p53 binding to HAUSP. Flag-tagged p53, HAUSP, or TRAF4 mutant proteins purified from transfected 293T cells were incubated together, and the mixtures were then immunoprecipitated using a HAUSP antibody; the associated p53 or TRAF4 was detected by Western blot analysis using specific antibodies. (E) TRAF domain deletion mutants lost the ability to regulate p53 induction. Expression vectors for Flag-tagged TRAF $\Delta$ R or TRAF $\Delta$ R/T mutant or the empty vector were transiently transfected into MCF-7 cells in the absence or presence of $2 \mathrm{mM}$ SNP treatment for $4 \mathrm{~h}$ before harvesting. Western blot analysis was performed using a p53-specific antibody or a TRAF4-specific antibody that recognized the $\Delta \mathrm{R}$ and $\Delta \mathrm{R} / \mathrm{T}$ mutants. $(F)$ TRAF4 blocked HAUSP-mediated p53 deubiquitination in vitro. Flag-p53, HA-Ub, and MDM2 expression vectors were cotransfected into 293T cells followed by MG132 treatment before harvesting. p53 protein was then purified by Flag affinity purification. HAUSP-mediated deubiquitination assays were carried out by incubating p53 protein with HAUSP protein in the absence or presence of different concentrations of TRAF4. The ubiquitination levels of p53 were detected by Western blot analysis using a HA-specific antibody. 
To test whether the TRAF domain of TRAF4 also is critical for interfering with p53-HAUSP interaction, we did in vitro binding assays using purified proteins. Flagtagged p53, HAUSP, or TRAF4 was transfected into 293T cells and purified by immunoprecipitation using a Flag antibody and then eluted with Flag peptides. The purified proteins were mixed in vitro and then immunoprecipitated with a HAUSP-specific antibody. As shown in Figure $5 \mathrm{D}$, p53 was pulled down with the HAUSP antibody (lane 1) but not the IgG control antibody (lane 4) in the absence of TRAF4, suggesting a specific interaction with HAUSP. The addition of the TRAF4 $\Delta \mathrm{R}$ mutant to the mixture significantly reduced the interaction between p53 and HAUSP (Fig. 5D, lane 2). Meanwhile TRAF4 $\Delta \mathrm{R}$ was detected by the TRAF4-specific antibody in the precipitates pulled down by HAUSP antibody. Although equal amounts of TRAF $\Delta \mathrm{R}$ and $\Delta \mathrm{R} / \mathrm{T}$ were added to the mixture, the $\Delta \mathrm{R} / \mathrm{T}$ mutant did not interact with HAUSP, and no alterations were evident in the p53-HAUSP interaction (Fig. 5D, lane 3). These results confirm that TRAF4 is a de facto competitor for p53 binding to HAUSP.

Consistent with its ability to interact with HAUSP, overexpression of the TRAF4 RING deletion mutant by transient transfection (Fig. 5E) was still able to decrease p53 protein level upon SNP treatment, while the TRAF domain deletion mutant failed to alter the level of p53 (Fig. 5E). These results indicate that the ability of TRAF4 to interact with HAUSP is critical for its role in regulating p53 stability.

\section{TRAF4 can block HAUSP-mediated p53 deubiquitination in vitro}

To demonstrate that the effect of TRAF4 on HAUSPmediated p53 deubiquitination in cells is not caused by indirect regulation of TRAF4 on other proteins such as E3 ubiquitin ligase, we performed an in vitro p53 deubiquitination assay. Flag-p53, HA-ubiquitin, and MDM2, which increases p53 ubiquitination, were cotransfected into $293 \mathrm{~T}$ cells, and the cells were then treated with MG132 to prevent the degradation of polyubiquitinated p53. The p53 protein purified from transfected 293T cell lysates was then incubated with purified HAUSP in the absence or presence of TRAF4 protein. As shown in Figure $5 \mathrm{~F}$, the polyubiquitination form of $\mathrm{p} 53$ can be detected, and the presence of HAUSP significantly reduced the level of p53 polyubiquitination, suggesting that the purified HAUSP was active in mediating deubiquitination in vitro. The addition of increasing amounts of TRAF4 protein, however, gradually decreased this HAUSP-mediated deubiquitination effect. Our results indicate that TRAF4 can regulate the level of p53 polyubiquitination through a direct interaction with HAUSP.

\section{HAUSP is the key molecule responsible for mediating TRAF4 regulation of p53 stability}

To further confirm that HAUSP is a key component in TRAF4-mediated p53 regulation, HAUSP was depleted by specific siRNA in either TRAF4-overexpressing stable cells or TRAF4 knockdown cells. p53 induction was significantly reduced in TRAF4 stable cells compared with control cells (Fig. 6A). Knockdown of HAUSP strongly decreased the level of p53 and abolished SNP-induced p53 up-regulation in both control and TRAF4 stable cells. This observation is consistent with previous reports that partial reduction of HAUSP by RNAi indeed destabilized the p53, while complete ablation of HAUSP stabilized the p53 due to MDM2 destabilization (Li et al. 2002, 2004; Cummins et al. 2004). We observed more dramatic p53 down-regulation caused by siHAUSP than we did for TRAF4 overexpression. The reason may be that less HAUSP was available for p53 deubiquitination when HAUSP was knocked down compared with TRAF4 competition. As shown in Figure 6B, HAUSP knocked down by specific siRNA also abolished the effect of siTRAF4 on p53 up-regulation. These results suggest that HAUSP is required for TRAF4-mediated p53 regulation.
A

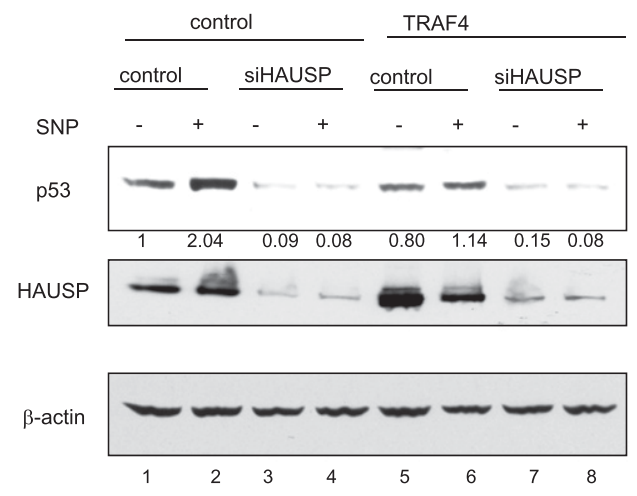

B

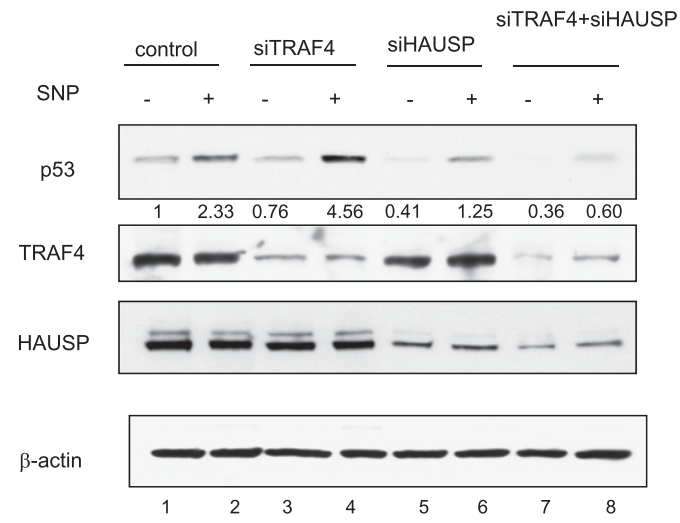

Figure 6. HAUSP is the key molecule responsible for mediating TRAF4 regulation of p53 stability. (A) HAUSP knockdown diminished TRAF4 overexpression effects on p53 induction. TRAF4 stable MCF-7 cells and control vector stable cells were transfected with siRNA against HAUSP or scramble control siRNA followed by $2 \mathrm{mM}$ SNP treatment for $4 \mathrm{~h}$. The levels of p53 and HAUSP were assessed by Western blot analysis using specific antibodies. (B) HAUSP knockdown abolished siTRAF4 effects on p53 induction. 
TRAF4 nuclear expression correlates with poor survival in breast cancer patients

To examine whether TRAF4 overexpression has clinical significance, we performed immunohistochemistry to analyze the expression of TRAF4 in 127 breast carcinoma samples. The breast cancer patients received adjuvant chemotherapy and/or radiotherapy and hormone therapy after surgical removal. Patients were followed up for 4-72 mo. The detailed characteristics of these patients have been described previously (Xia et al. 2004). More significant nuclear staining of TRAF4 in tumor samples was observed compared with normal breast tissues (Supplemental Fig. S10A). In MCF-7 cells, we found that TRAF4 and p53 were predominantly localized in the nucleus, while HAUSP was equally distributed between the nucleus and the cytoplasm, suggesting that the competition between TRAF4 and p53 mainly occurs in the nucleus (Fig. 7A). The overall survival of these breast cancer patients after surgery was plotted by use of the Kaplan-Meier method. As shown in Figure 7B, high TRAF4 nuclear expression is significantly associated with poor overall survival in these patients $(P<0.003)$. To correlate the TRAF4 expression with p53 function, we analyzed TRAF4 expression and the expression of the p53 target gene BID, a "chemosensitivity gene" (Sax et al. 2002), in ER-positive breast tumors, since p53 mutation rate is lower in these tumors (Curtis et al. 2012). There were 12 cases of ER-positive tumors. A significant inverse correlation between TRAF4 and BID expression was observed $(r=-0.598, P=0.038)$ in these samples (Fig. 7C; Supplemental Fig. S10B). These results suggest that TRAF4 overexpression also down-regulates p53 function in ER-positive breast tumors. Altogether, our results provide clinical evidence that TRAF4 overexpression is associated with a poor response to therapy.
A

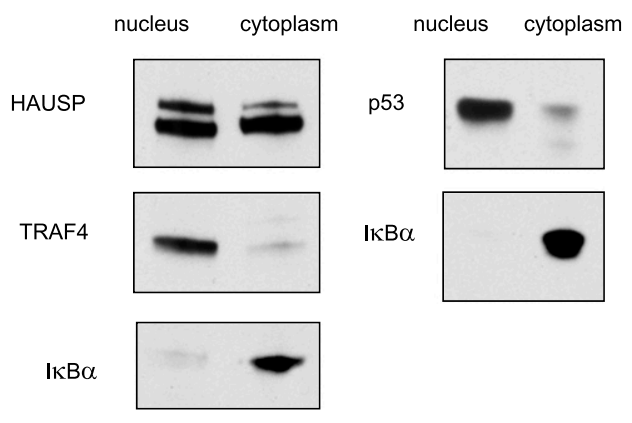

C

\begin{tabular}{|c|c|c|c|c|}
\hline & & \multicolumn{3}{|c|}{ TRAF4 } \\
\hline & & negative & positive & total \\
\hline \multirow{3}{*}{ BID } & - & $0(0 \%)$ & $5(41.7 \%)$ & $5(41.7 \%)$ \\
\hline & + & $4(33.3 \%)$ & $3(25 \%)$ & $7(58.3 \%)$ \\
\hline & total & $4(33.3 \%)$ & $8(66.7 \%)$ & $12(100 \%)$ \\
\hline $\begin{array}{l}\text { Inverse } \\
\text { correlation }\end{array}$ & & $9 / 12(75 \%)$ & & $\begin{array}{c}r=-0.598 \\
(p=0.038)\end{array}$ \\
\hline
\end{tabular}

B

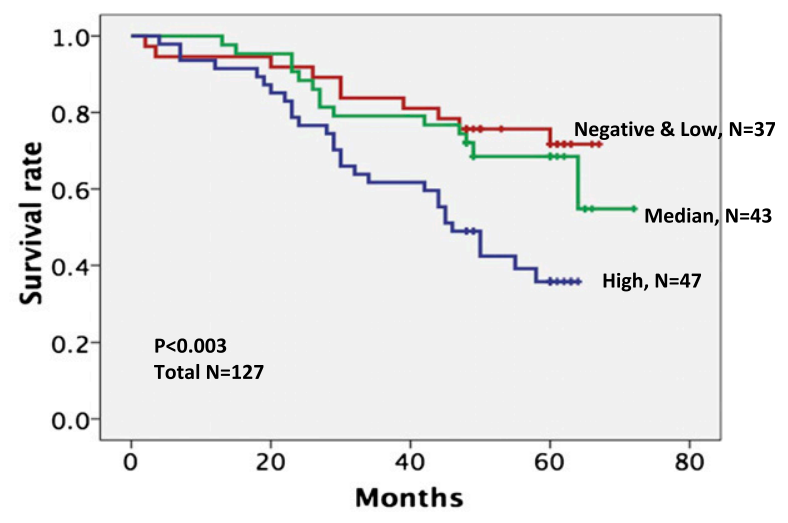

D

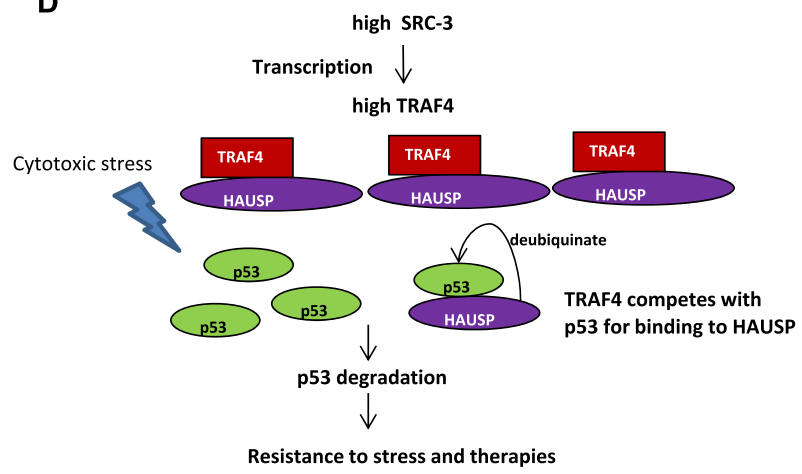

Figure 7. High TRAF4 nuclear expressions were correlated with poor survival in breast cancer patients. (A) TRAF4 and p53 were mainly localized in the nucleus of MCF-7 cells. The nuclear and cytoplasmic fractions of MCF-7 lysates were separated, and the expression levels of TRAF4, p53, and HAUSP in each fraction $(50 \mu \mathrm{g})$ were determined by Western blot analysis. IкB $\alpha$ is mainly localized in the cytoplasm and is an indicator of successful separation of the cytoplasmic fraction from the nuclear fraction. $(B)$ KaplanMeier analysis of overall survival curves of TRAF4 nuclear expressions in breast cancer patients is shown. $(C)$ Relationships between the expression of TRAF4 and BID in surgical specimens of ER-positive breast cancer. Expression patterns of these two molecules in the ER-positive breast cancer samples were determined and summarized. Inverse correlation between TRAF4 and BID was analyzed using SPSS Pearson $\chi^{2}$ test $(P=0.038)$. A $P$-value of $>0.05$ was set as the criterion for statistical significance. $(D)$ The working model of resistance to cytotoxic stress in SRC-3-overexpressing cells. In SRC-3-overexpressing cancer cells, TRAF4 is highly expressed and binds to the N-terminal TRAF-like domain of the deubiquitinase HAUSP, preventing the binding of p53 to the same region of HAUSP. This binding competition results in decreased p53 deubiquitination and protein levels, subsequently reducing stressinduced cell apoptosis. 
Yi et al.

\section{Discussion}

It is well documented that SRC-3 overexpression and its gene amplification are associated with a wide spectrum of malignant tumors (for review, see Xu et al. 2009; Gojis et al. 2010). However, its role in drug resistance was not appreciated until recently (Etemadmoghadam et al. 2009; He et al. 2009; Cai et al. 2010). Using a lentiviral cDNA library in a "rescue screening" for genes that facilitate SRC-3-depleted cell survival under cytotoxic stress conditions, we identified SRC-3 downstream-regulated genes important for this effect. We demonstrate here that SRC-3 deregulates p53 induction upon stress and that TRAF4 is a key downstream player in mediating this process. Under normal conditions, p53 levels are controlled by the balance between ubiquitin ligases, such as MDM2, and the deubiquitinases, including HAUSP. Under stress, ubiquitin ligases dissociate from $\mathrm{p} 53$, and deubiquitinases such as HAUSP function to protect p53 from protein degradation, resulting in cell apoptosis and/ or cell cycle arrest. In SRC-3-overexpressing cancer cells, TRAF4 is highly expressed and binds to the $\mathrm{N}$-terminal TRAF-like domain of HAUSP, preventing the binding of p53 to the same region of HAUSP. This binding competition results in decreased p53 protein levels and subsequently reduces stress-induced cell apoptosis (Fig. 7D).

A similar turnover mechanism has been shown to be used by MDM2 (Hu et al. 2006; Sheng et al. 2006), the viral protein EBNA1 (Saridakis et al. 2005), and TSPYL5 (Epping et al. 2011). Although MDM2 also is deubiquitinated by HAUSP and is the preferred substrate under normal conditions, its interaction affinity with HAUSP is significantly reduced under conditions of cell stress (Meulmeester et al. 2005). Stress also induces MDM2 dissociation from $\mathrm{p} 53$, resulting in $\mathrm{p} 53$ protein stabilization. We found that overexpression of MDM2 only decreased p53 protein under normal conditions but not in SNP-treated cells (Supplemental Fig. S11). Therefore, it is unlikely that MDM2 is involved in TRAF4-mediated p53 regulation under nitric oxide stress. Our in vitro proteinbinding assays and in vitro deubiquitination assays using purified proteins further confirm that TRAF4 can directly compete with p53 for HAUSP binding rather than indirectly affecting other p53-associated proteins.

The TRAF domain of TRAF4 is required for its interaction with the HAUSP TRAF-like domain and to regulate p53 stability (Fig. 5C,E). This domain in TRAF family members is highly conserved. It mediates TRAF homodimerization, trimerization, or heterodimerization with other TRAFs (Rothe et al. 1994; Bradley and Pober 2001). The interaction between TRAF4 and HAUSP may be analogous to the heterodimerization between other TRAF family members. Similar to the structures of all other TRAF domain proteins, the $\mathrm{N}$ terminus of HAUSP forms an eight-stranded anti-parallel $\beta$ sandwich (Saridakis et al. 2005), and p53 binds to a shallow depression on the surface of this structure (Sheng et al. 2006). Binding of TRAF4 to this region appears to block p53 access. The N-terminal RING domains of TRAF2, TRAF6, and TRAF7 were reported to contain E3 ubiquitin ligase activities that catalyze K63 or K48 ubiquitination (Bradley and Pober 2001; Yang et al. 2009; Zotti et al. 2011). Deletion of this domain did not compromise the ability of TRAF4 to regulate p53 (Fig. 5E). Instead, it significantly increased TRAF4 protein stability (data not shown). This result excludes the possibility that the increased p53 ubiquitination observed in Figure 4B in the presence of TRAF4 is mediated by the potential ubiquitin ligase activity of TRAF4. Since TRAF4 is expressed at basal levels in normal tissues but is overexpressed in a wide spectrum of cancer tissues (Camilleri-Broet et al. 2007), it is likely that its protein stability may be tightly controlled in normal conditions, while it is aberrantly regulated in cancers through its RING domain.

We observed that TRAF4 nuclear expression levels were significantly associated with poor survival in breast cancer patients after adjuvant therapy (Fig. 7B), implying that the nuclear function of TRAF4 is critical in affecting patients' responses to therapy. This clinical observation is consistent with our findings that TRAF4 plays a key role in promoting p53 protein destabilization in the nucleus. TRAF4 can be localized in the plasma membrane, cytoplasm, and nucleus (Regnier et al. 1995; Kedinger et al. 2008). Interestingly, it has been found to be predominantly localized in the cytoplasm of normal tissues (Krajewska et al. 1998; Kedinger et al. 2008). We also found predominant cytoplasmic staining of TRAF4 in normal breast tissues in contrast to that observed for tumor tissues (Supplemental Fig. S10A). In cancer tissues, both cytoplasmic and nuclear staining were observed, and in some cases, exclusive nuclear staining was seen for TRAF4 (Camilleri-Broet et al. 2007). It appears that the subcellular distribution of TRAF4 is altered in cancers, and greater nuclear expression is associated with poor prognosis. It is still not clear how TRAF4 nuclear localization is regulated in cancers. A TRAF domain deletion was previously reported to abolish TRAF4 nuclear localization despite the fact that no nuclear localization signal was found in this region of the protein (Glauner et al. 2002; Kedinger et al. 2008). Since this region also is involved in protein-protein interactions, it may be possible that the nuclear localization of TRAF4 is assisted by an unknown protein that interacts with the TRAF domain and that this interaction is especially relevant in tumor cells.

In normal cells, tumor suppressors function to control excessive cell proliferation. Strong mitogenic signaling pathways often activate the tumor suppressor p53, which functions as a counterbalance that leads to cell growth arrest. To overcome this suppression brake, tumor development is usually accompanied by inhibition or loss of tumor suppressor functions. As an oncogenic coactivator, SRC-3 has been shown to activate multiple pathways (such as nuclear receptor, E2F, and AKT signaling) that can promote cancer cell proliferation (Yan et al. 2006). In addition to these proliferation pathways, we now demonstrate another oncogenic role for SRC-3 through its ability to directly inhibit the tumor suppressor p53. SRC-3 accomplishes this by promoting the expression of TRAF4, leading to the suppression of proteins responsible for $\mathrm{p} 53$ 
protein stabilization in response to cellular stress. This function provides further growth advantage for tumor cells to overexpress SRC-3 in order to proliferate.

p53 is frequently mutated $(\sim 50 \%)$ in cancers, and its mutation plays a central role in drug resistance. Therapeutic strategies to restore p53 function in tumors are currently in development (Tan and White 2008). In breast cancers, however, only $\sim 20 \%$ of tumors possess p53 mutations (Gasco et al. 2003; Chrisanthar et al. 2011; Curtis et al. 2012). Thus, aberrant regulation of wild-type p53 activity and protein stability are more likely to play a role in drug resistance in these instances. Our analysis on the inverse correlation between SRC-3 protein levels and the levels of p53 target gene BID in breast-invasive carcinoma samples (Fig. 3A,B) implies that SRC-3 can negatively regulate wild-type p53 function in breast cancer patients. The ability of SRC-3 and TRAF4 to destabilize p53 can play an important role in mediating breast cancer resistance to drug therapies and for breast cancer cells to proliferate in the context of the cytotoxic stress that accompanies activation of mitogenic pathways. Because of SRC-3's ability to abrogate p53 function, our results suggest that SRC-3 overexpression may be especially important in tumors in which p53 is not mutated.

\section{Materials and methods}

\section{In vitro competition assay}

p53, HAUSP, and TRAF4 were synthesized using an in vitro transcription and translation kit according to the manufacturer's instruction (Promega). Ten microliters of p53 was incubated with $10 \mu \mathrm{L}$ of HAUSP in the absence or presence of TRAF4 (10 or $20 \mu \mathrm{L}$ ) for $30 \mathrm{~min}$ on ice. The reaction mixture was then subjected to co-IP using a HAUSP specific antibody (Bethyl Laboratories). Western blot analysis was then performed to analyze HAUSP-associated p53.

Flag-p53 was purified from transfected 293T cells using Flag $\mathrm{M} 2$ beads in lysis buffer $(50 \mathrm{mM}$ Tris- $\mathrm{HCl}$ at $\mathrm{pH} 7.8,137 \mathrm{mM}$ $\mathrm{NaCl}, 10 \mathrm{mM} \mathrm{NaF}, 1 \mathrm{mM}$ EDTA, $1 \%$ Triton X-100, $0.2 \%$ sarkosyl, $1 \mathrm{mM}$ DTT, 10\% glycerol). After extensive washing, Flag-p53 was eluted by adding $150 \mathrm{ng} / \mu \mathrm{L} 3 \times$ Flag peptide in TBS buffer. Flag-HAUSP and Flag-TRAF4 deletion mutants were transfected into $293 \mathrm{~T}$ cells and purified using Flag M2 beads using the same procedure described above. Purified p53 was incubated with HAUSP in the absence or presence of TRAF4 and was coimmunoprecipitated by the HAUSP antibody.

\section{Immunohistochemistry}

The procedure for TRAF4 immunostaining in breast cancer tumor samples and the scoring of immunoreactivity were essentially the same as described previously (Xia et al. 2004). TRAF4 antibody was obtained from Santa Cruz Biotechnology (H-72) and used at 1:50 dilution. BID antibody was obtained from Abcam. The difference in survival distribution was analyzed by log-rank test. Statistical analysis was performed with SAS 8.0 and S-plus 2000 software. The expression of TRAF4 and BID in 12 ER-positive breast tumors was scored by the cross-product (H score) of the percentage of tumors cells staining at each of the staining intensities (Camp et al. 1999).

The breast tumor tissue array (Pantomics) contained 75 cases and 150 cores of normal tissue and different stages of breast tumor material. Immunohistochemistry was performed using a SRC-3 antibody (1:100) and a TRAF4 antibody. Each SRC-3- or TRAF4-stained sample was assigned a score ranging from 0 to 3 , with 0 for negative and 3 for very strong staining. The score of each case was then averaged between duplicate cores. The Pearson Product Moment correlation coefficient and the $P$-value of SRC-3 and TRAF4 expression in all samples were calculated using statistics software from Wessa (http://www.wessa.net).

Additional materials and methods are described in the Supplemental Material.

\section{Acknowledgments}

We thank Dr. Wei Gu (Columbia University) for kindly providing the HAUSP expression vector, and Dr. Ming-Jer Tsai for critical reading and editing of the manuscript. This work is supported by NIH grant (HD8818), Welch foundation (Q1521), CPRIT grant (B.W.O. CPRIT), and Komen Foundation grant (to B.W.O.). R.C.W. was supported in part by grants from Dan L. Duncan Cancer Center, Baylor College of Medicine (NCI Cancer Center Support Grant P30CA125123), and Susan G. Komen for the Cure (BCTR0707225).

\section{References}

Anzick SL, Kononen J, Walker RL, Azorsa DO, Tanner MM, Guan XY, Sauter G, Kallioniemi OP, Trent JM, Meltzer PS. 1997. AIB1, a steroid receptor coactivator amplified in breast and ovarian cancer. Science 277: 965-968.

Bazzett LB, Watkins CS, Gercel-Taylor C, Taylor DD. 1999. Modulation of proliferation and chemosensitivity by procathepsin D and its peptides in ovarian cancer. Gynecol Oncol 74: $181-187$.

Bradley JR, Pober JS. 2001. Tumor necrosis factor receptorassociated factors (TRAFs). Oncogene 20: 6482-6491.

Cai D, Shames DS, Raso MG, Xie Y, Kim YH, Pollack JR, Girard L, Sullivan JP, Gao B, Peyton M, et al. 2010. Steroid receptor coactivator-3 expression in lung cancer and its role in the regulation of cancer cell survival and proliferation. Cancer Res 70: 6477-6485.

Camilleri-Broet S, Cremer I, Marmey B, Comperat E, Viguie F, Audouin J, Rio MC, Fridman WH, Sautes-Fridman C, Regnier CH. 2007. TRAF4 overexpression is a common characteristic of human carcinomas. Oncogene 26: 142-147.

Camp RL, Rimm EB, Rimm DL. 1999. Met expression is associated with poor outcome in patients with axillary lymph node negative breast carcinoma. Cancer 86: 2259-2265.

Cherfils-Vicini J, Vingert B, Varin A, Tartour E, Fridman WH, Sautes-Fridman C, Regnier CH, Cremer I. 2008. Characterization of immune functions in TRAF4-deficient mice. Immunology 124: 562-574.

Chrisanthar R, Knappskog S, Lokkevik E, Anker G, Ostenstad B, Lundgren S, Risberg T, Mjaaland I, Skjonsberg G, Aas T, et al. 2011. Predictive and prognostic impact of TP53 mutations and MDM2 promoter genotype in primary breast cancer patients treated with epirubicin or paclitaxel. PLOS ONE 6: e19249.

Cummins JM, Rago C, Kohli M, Kinzler KW, Lengauer C, and Vogelstein B. 2004. Tumour suppression: Disruption of HAUSP gene stabilizes p53. Nature doi: 10.1038/nature02501.

Curtis C, Shah SP, Chin SF, Turashvili G, Rueda OM, Dunning MJ, Speed D, Lynch AG, Samarajiwa S, Yuan Y, et al. 2012. The genomic and transcriptomic architecture of 2,000 breast tumours reveals novel subgroups. Nature 486: 346-352.

Dihge L, Bendahl PO, Grabau D, Isola J, Lovgren K, Ryden L, Ferno M. 2008. Epidermal growth factor receptor (EGFR) and 
the estrogen receptor modulator amplified in breast cancer (AIB1) for predicting clinical outcome after adjuvant tamoxifen in breast cancer. Breast Cancer Res Treat 109: 255-262.

Epping MT, Meijer LA, Krijgsman O, Bos JL, Pandolfi PP, Bernards R. 2011. TSPYL5 suppresses p53 levels and function by physical interaction with USP7. Nat Cell Biol 13: 102-108.

Etemadmoghadam D, deFazio A, Beroukhim R, Mermel C, George J, Getz G, Tothill R, Okamoto A, Raeder MB, Harnett $\mathrm{P}$, et al. 2009. Integrated genome-wide DNA copy number and expression analysis identifies distinct mechanisms of primary chemoresistance in ovarian carcinomas. Clin Cancer Res 15: 1417-1427.

Gasco M, Yulug IG, Crook T. 2003. TP53 mutations in familial breast cancer: Functional aspects. Hum Mutat 21: 301-306.

Glauner H, Siegmund D, Motejadded H, Scheurich P, Henkler F, Janssen O, Wajant H. 2002. Intracellular localization and transcriptional regulation of tumor necrosis factor (TNF) receptor-associated factor 4 (TRAF4). Eur I Biochem 269: $4819-4829$.

Gojis O, Rudraraju B, Alifrangis C, Krell J, Libalova P, Palmieri C. 2010. The role of steroid receptor coactivator-3 (SRC-3) in human malignant disease. Eur I Surg Oncol 36: 224-229.

Harper CE, Cook LM, Patel BB, Wang J, Eltoum IA, Arabshahi A, Shirai T, Lamartiniere CA. 2009. Genistein and resveratrol, alone and in combination, suppress prostate cancer in SV-40 tag rats. Prostate 69: 1668-1682.

He LR, Liu MZ, Li BK, Rao HL, Deng HX, Guan XY, Zeng YX, Xie D. 2009. Overexpression of AIB1 predicts resistance to chemoradiotherapy and poor prognosis in patients with primary esophageal squamous cell carcinoma. Cancer Sci 100: $1591-1596$

Hu M, Gu L, Li M, Jeffrey PD, Gu W, Shi Y. 2006. Structural basis of competitive recognition of p53 and MDM2 by HAUSP/USP7: Implications for the regulation of the p53MDM2 pathway. PLoS Biol 4: e27.

Janicke RU, Sprengart ML, Wati MR, Porter AG. 1998. Caspase-3 is required for DNA fragmentation and morphological changes associated with apoptosis. J Biol Chem 273: 93579360 .

Kedinger V, Rio MC. 2007. TRAF4, the unique family member. Adv Exp Med Biol 597: 60-71.

Kedinger V, Alpy F, Baguet A, Polette M, Stoll I, Chenard MP, Tomasetto C, Rio MC. 2008. Tumor necrosis factor receptorassociated factor 4 is a dynamic tight junction-related shuttle protein involved in epithelium homeostasis. PLOS ONE 3: e3518.

Kirkegaard T, McGlynn LM, Campbell FM, Muller S, Tovey SM, Dunne B, Nielsen KV, Cooke TG, Bartlett JM. 2007. Amplified in breast cancer 1 in human epidermal growth factor receptor-positive tumors of tamoxifen-treated breast cancer patients. Clin Cancer Res 13: 1405-1411.

Krajewska M, Krajewski S, Zapata JM, Van Arsdale T, Gascoyne RD, Berern K, McFadden D, Shabaik A, Hugh J, Reynolds A, et al. 1998. TRAF-4 expression in epithelial progenitor cells. Analysis in normal adult, fetal, and tumor tissues. Am Pathol 152: 1549-1561.

Kuang SQ, Liao L, Zhang H, Lee AV, O'Malley BW, Xu J. 2004. AIB1/SRC-3 deficiency affects insulin-like growth factor I signaling pathway and suppresses $\mathrm{v}$-Ha-ras-induced breast cancer initiation and progression in mice. Cancer Res 64: $1875-1885$.

Lee SK, Kim HJ, Na SY, Kim TS, Choi HS, Im SY, Lee JW. 1998. Steroid receptor coactivator-1 coactivates activating protein1-mediated transactivations through interaction with the c-Jun and c-Fos subunits. J Biol Chem 273: 16651-16654.
Leto G, Tumminello FM, Crescimanno M, Flandina C, Gebbia N. 2004. Cathepsin D expression levels in nongynecological solid tumors: Clinical and therapeutic implications. Clin Exp Metastasis 21: 91-106.

Li M, Chen D, Shiloh A, Luo J, Nikolaev AY, Qin J, Gu W. 2002. Deubiquitination of p53 by HAUSP is an important pathway for p53 stabilization. Nature 416: 648-653.

Li M, Brooks CL, Kon N, Gu W. 2004. A dynamic role of HAUSP in the p53-Mdm2 pathway. Mol Cell 13: 879-886.

Li R, Chen Y, Shu WX, Chen Z, Ke WJ. 2009a. Involvement of SRC-3 in deguelin-induced apoptosis in Jurkat cells. Int $I$ Hematol 89: 628-635.

Li R, Chen Y, Zeng LL, Shu WX, Zhao F, Wen L, Liu Y. 2009b. Gambogic acid induces G0/G1 arrest and apoptosis involving inhibition of SRC-3 and inactivation of Akt pathway in K562 leukemia cells. Toxicology 262: 98-105.

Longley DB, Johnston PG. 2005. Molecular mechanisms of drug resistance. J Pathol 205: 275-292.

Meulmeester E, Maurice MM, Boutell C, Teunisse AF, Ovaa H, Abraham TE, Dirks RW, Jochemsen AG. 2005. Loss of HAUSP-mediated deubiquitination contributes to DNA damage-induced destabilization of $\mathrm{Hdmx}$ and $\mathrm{Hdm} 2 . \mathrm{Mol}$ Cell 18: 565-576.

Murphy LC, Simon SL, Parkes A, Leygue E, Dotzlaw H, Snell L, Troup S, Adeyinka A, Watson PH. 2000. Altered expression of estrogen receptor coregulators during human breast tumorigenesis. Cancer Res 60: 6266-6271.

Osborne CK, Bardou V, Hopp TA, Chamness GC, Hilsenbeck SG, Fuqua SA, Wong J, Allred DC, Clark GM, Schiff R. 2003. Role of the estrogen receptor coactivator AIB1 (SRC-3) and HER-2/neu in tamoxifen resistance in breast cancer. I Natl Cancer Inst 95: 353-361.

Regnier CH, Tomasetto C, Moog-Lutz C, Chenard MP, Wendling C, Basset P, Rio MC. 1995. Presence of a new conserved domain in CART1, a novel member of the tumor necrosis factor receptor-associated protein family, which is expressed in breast carcinoma. J Biol Chem 270: 25715-25721.

Regnier CH, Masson R, Kedinger V, Textoris J, Stoll I, Chenard MP, Dierich A, Tomasetto C, Rio MC. 2002. Impaired neural tube closure, axial skeleton malformations, and tracheal ring disruption in TRAF4-deficient mice. Proc Natl Acad Sci 99: 5585-5590.

Rothe M, Wong SC, Henzel WJ, Goeddel DV. 1994. A novel family of putative signal transducers associated with the cytoplasmic domain of the $75 \mathrm{kDa}$ tumor necrosis factor receptor. Cell 78: 681-692.

Saridakis V, Sheng Y, Sarkari F, Holowaty MN, Shire K, Nguyen T, Zhang RG, Liao J, Lee W, Edwards AM, et al. 2005. Structure of the p53 binding domain of HAUSP/USP7 bound to Epstein-Barr nuclear antigen 1: Implications for EBVmediated immortalization. Mol Cell 18: 25-36.

Sax JK, Fei P, Murphy ME, Bernhard E, Korsmeyer SJ, El-Deiry WS. 2002. BID regulation by p53 contributes to chemosensitivity. Nat Cell Biol 4: 842-849.

Sheng Y, Saridakis V, Sarkari F, Duan S, Wu T, Arrowsmith CH, Frappier L. 2006. Molecular recognition of p53 and MDM2 by USP7/HAUSP. Nat Struct Mol Biol 13: 285-291.

Tan TT, White E. 2008. Therapeutic targeting of death pathways in cancer: Mechanisms for activating cell death in cancer cells. Adv Exp Med Biol 615: 81-104.

Torres-Arzayus MI, De Mora JF, Yuan J, Vazquez F, Bronson R, Rue M, Sellers WR, Brown M. 2004. High tumor incidence and activation of the PI3K/AKT pathway in transgenic mice define AIB1 as an oncogene. Cancer Cell 6: 263-274.

Wu MY, Fu J, Xu J, O'Malley BW, Wu RC. 2012. Steroid receptor coactivator 3 regulates autophagy in breast cancer cells 
through macrophage migration inhibitory factor. Cell Res 22: $1003-1021$.

Xia W, Chen JS, Zhou X, Sun PR, Lee DF, Liao Y, Zhou BP, Hung MC. 2004. Phosphorylation/cytoplasmic localization of p21Cip1/WAF1 is associated with HER2/neu overexpression and provides a novel combination predictor for poor prognosis in breast cancer patients. Clin Cancer Res 10: 3815-3824.

$\mathrm{Xu} \mathrm{J,} \mathrm{Wu} \mathrm{RC,} \mathrm{O'Malley} \mathrm{BW.} \mathrm{2009.} \mathrm{Normal} \mathrm{and} \mathrm{cancer-related}$ functions of the p160 steroid receptor co-activator (SRC) family. Nat Rev Cancer 9: 615-630.

Yan J, Tsai SY, Tsai MJ. 2006. SRC-3/AIB1: Transcriptional coactivator in oncogenesis. Acta Pharmacol Sin 27: 387-394.

Yan J, Erdem H, Li R, Cai Y, Ayala G, Ittmann M, Yu-Lee LY, Tsai SY, Tsai MJ. 2008. Steroid receptor coactivator-3/AIB1 promotes cell migration and invasiveness through focal adhesion turnover and matrix metalloproteinase expression. Cancer Res 68: 5460-5468.

Yang WL, Wang J, Chan $\mathrm{CH}$, Lee SW, Campos AD, Lamothe B, Hur L, Grabiner BC, Lin X, Darnay BG, et al. 2009. The E3 ligase TRAF6 regulates Akt ubiquitination and activation. Science 325: 1134-1138.

Zapata JM, Pawlowski K, Haas E, Ware CF, Godzik A, Reed JC. 2001. A diverse family of proteins containing tumor necrosis factor receptor-associated factor domains. I Biol Chem 276: 24242-24252.

Zhao C, Yasui K, Lee CJ, Kurioka H, Hosokawa Y, Oka T, Inazawa J. 2003. Elevated expression levels of NCOA3, TOP1, and TFAP2C in breast tumors as predictors of poor prognosis. Cancer 98: 18-23.

Zotti T, Uva A, Ferravante A, Vessichelli M, Scudiero I, Ceccarelli M, Vito P, Stilo R. 2011. TRAF7 protein promotes Lys-29-linked polyubiquitination of ІкB kinase $(\mathrm{IKK} \gamma) / \mathrm{NF}-\kappa \mathrm{B}$ essential modulator (NEMO) and p65/RelA protein and represses NF-кB activation. J Biol Chem 286: 22924-22933. 


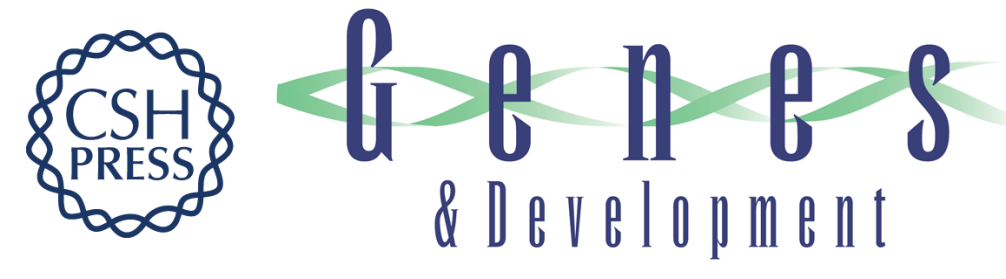

\section{SRC-3 coactivator regulates cell resistance to cytotoxic stress via TRAF4-mediated p53 destabilization}

Ping Yi, Weiya Xia, Ray-Chang Wu, et al.

Genes Dev. 2013, 27:

Access the most recent version at doi:10.1101/gad.203760.112

Supplemental
Material $\quad$ http://genesdev.cshlp.org/content/suppl/2013/02/06/27.3.274.DC1

References This article cites 51 articles, 15 of which can be accessed free at: http://genesdev.cshlp.org/content/27/3/274.full.html\#ref-list-1

License

Email Alerting

Service
Receive free email alerts when new articles cite this article - sign up in the box at the top right corner of the article or click here.

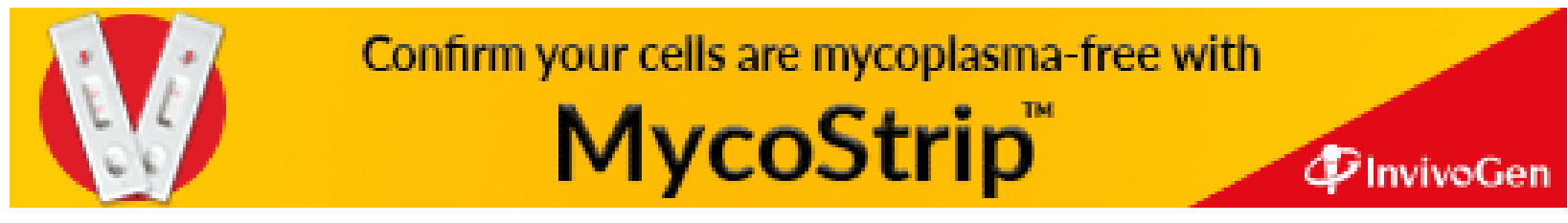

